\title{
La desigualdad social y la precarización de las condiciones laborales en Costa Rica
}

\author{
Social inequality and precarious working conditions \\ in Costa Rica
}
A desigualdade social e a precarização das condições de trabalho na Costa Rica

\section{Marta Isabel Valverde Brenes*}

\section{RESUMEN}

El ejercicio del derecho al trabajo como derecho humano, constituye una lucha y una conquista social gestada en contextos sociohistóricos divergentes, con regulaciones normativas cambiantes y sujetas a las demandas de los modelos político-económicos de un momento en particular.

Lo anterior conlleva manifestaciones de desigualdad social en las diversas poblaciones en el ámbito laboral, en donde convergen variedad de aristas individuales, colectivas y estructurales que generan la precarización de las condiciones de trabajo.

Esto es una realidad histórica que trasciende sus expresiones en el mundo laboral, pues el deterioro al ejercicio pleno del derecho al trabajo se conjuga con la violación a otros derechos que garantizan el desarrollo integral de las personas.

De esta manera, es necesario repensar aquellas acciones afirmativas que trasciendan y permitan movilizarse hacia la equidad y la justicia social. Así, este artículo pretende reflejar algunas apreciaciones sobre la realidad del mundo del trabajo en Costa Rica.

\section{ABSTRACT}

The exercise of the human right to work constitutes a struggle and social conquest produced in divergent socio-historical con-
Palabras

clave: trabajo, precarización laboral, desigualdades sociales, derechos humanos.

Key words: work, labor precariousness,

Costarricense. Licenciada en Trabajo Social. Especialista en Políticas Públicas para la igualdad en América Latina. E-mail: isitaster@gmail.com 
texts, with changing regulations that are subject to the demands of the political and economic models of a particular time.

social inequalities, human rights.

The foregoing entails manifestations of social inequality in the various working-class populations, where a variety of individual, collective and structural aspects converge to generate precarious working conditions.

This is a historical reality that transcends its expressions in the world of labor, since the impairment of the full exercise of the right to work is combined with the violation of other rights that guarantee the integral human development.

Therefore, it is necessary to rethink those transcending affirmative actions in order to move towards equity and social justice. This article is aimed at reflecting on the reality of the workforce in Costa Rica and its perception worldwide.

\section{RESUMO}

O exercício do direito ao trabalho como um direito humano constitui uma luta e uma conquista social que surgiu em contextos sócio-históricos divergentes, com regulamentações em constante mudança e sujeitas às exigências dos modelos político-econômicos de determinado momento.

Isto implica manifestações de desigualdade social no âmbito laboral nas diversas populações, onde diversos aspectos individuais, coletivos e estruturais convergem gerando a precarização das condições de trabalho.

Esta é uma realidade histórica que transcende suas expressões no mundo laboral, já que a deterioração do pleno exercício do direito ao trabalho se combina com a violação de outros direitos que garantem o desenvolvimento integral das pessoas.

Desta forma, é necessário repensar aquelas ações afirmativas que transcendem e permitem a mobilização em prol da equidade e da justiça social. Assim, este artigo visa refletir sobre algumas percepções relacionadas à realidade do mundo laboral na Costa Rica.
Palavras-chave:

trabalho,

precarização

laboral,

desigualdades

sociais, direitos

humanos.

\section{Introducción}

Históricamente, el trabajo ha sido construido como una categoría ontológica fundante, es decir, una construcción que establece en donde nace la sociedad; por ende, es determinante del ser social. A partir de esto, el desarrollo de las sociedades considera el contexto sociohistórico con sus manifestaciones sociales, políticas, económicas, culturales e ideológicas, las cuales, a su vez, han generado cambios y aristas de análisis en torno al trabajo.

Aunado a esto, el proceso histórico conlleva repensar la adopción de modelos de políticas de mercado neoliberales, los cuales han derivado en la proliferación de las desigualdades sociales, no exentas sus evidencias en el mundo del trabajo. Por ende, el modelo neoliberal es un modelo de acumulación de capital, cuyo énfasis está en el mercado, el cual en sí mismo conlleva a la informalidad, el desempleo, el subempleo, la desprotección laboral y la pobreza.

Según estima el Programa Estado de la Nación (2017) y el Instituto Nacional de Estadísticas y Censos (2017), en Costa Rica las condiciones laborales han presentado diversas variaciones asociadas con el deterioro en la calidad de los puestos, tercerización, reducción de garantías sociales, informalidad, sumado a desigualdades dadas por género (el trabajo remunerado y no remunerado), edad, nacionalidad, clase social, formación educativa. La suma de estas condiciones genera en la población vulnerabilidad social, que limita el bienestar integral y amplía la brecha entre clases sociales.

Dicho análisis hace repensar el modelo de Estado imperante: el achicamiento del sector público, la proliferación de la visión del otro, las relaciones de poder y, por ende, el escenario o elementos para la generación de políticas sociales reducidas. A partir de esto, surgen interrogantes asociadas a la forma de materialización de las desigualdades sociales en las condiciones laborales de las y los trabajadores, mismas que, para el caso específico de esta propuesta, tendrán una periodicidad de estudio de ocho años, lo cual se circunscribe ante algunas particularidades presentes en Costa Rica.

Durante 2004, el Tratado de Libre Comercio entre Estados Unidos y Centroamérica se establece como un acuerdo definitivo y una propuesta de política comercial, con lo cual se instaura "un marco adecuado 
para mejorar y aumentar las exportaciones de Costa Rica al principal mercado del mundo y para promover la inversión, el crecimiento económico y nuevas oportunidades de empleo en el país" (Ministerio de Comercio Exterior, 2004, p. 7).

El mismo fue enviado a referéndum en $2007 \mathrm{y}$, a pesar de diversas luchas y movimientos sociales, termina por ratificarse y entrar en vigencia durante 2009. En esos cuestionamientos y divergencia de posiciones, muchos de ellos se relacionaron con el supuesto crecimiento de empleo; sin embargo, las valoraciones existentes sobre esto son incipientes y se contrasta con información sobre la condición del trabajo en el país que se estima de riesgo.

Según Morales (2011), en alusión al impacto de la lógica neoliberal en las condiciones laborales, se estima que "la flexibilización laboral constituye una norma, donde la incertidumbre de las clases trabajadoras, así como la precarización de sus condiciones laborales, son vistas no solo como aceptables, sino como el orden normal de las cosas" (p. 24).

Aunado a esto, el Programa Estado de la Nación (2017) refiere que, hacia finales de 2016 e inicios de 2017, la oferta del mercado de trabajo dio señales de recuperación, sin embargo, se estima apresurado asegurar la efectividad de las mejoras, dado que la información disponible hasta el momento muestra resultados dispares y avances no generalizados, pues la reducción del desempleo y el crecimiento de los puestos de trabajo se contrastan con la expansión de la informalidad y la persistencia de brechas de género.

Por ende, es de cuestionar las condiciones laborales actuales, las demandas del mercado laboral que se contraponen con la necesidad de satisfacción de necesidades básicas de las diversas poblaciones, las limitaciones en los procesos educativos y su tendiente dirección a atender las demandas específicas del mercado, y otras inequidades derivadas de esto.

Vinculado a lo anterior, durante 2018 se dio una ardua discusión sobre el proyecto de Ley 20.580, hoy Ley N 9635 "Ley de Fortalecimiento de las Finanzas Públicas", el cual generó grandes contrastes entre diferentes poblaciones y grupos de poder político-económico; y, que se presume, acentuará las condiciones laborales precarias de la población y la posibilidad de gozar de condiciones de bienestar, con un amplio recorte para las políticas sociales destinadas a igualdad y justicia social.

De esta manera, es de interés indagar las condiciones de trabajo existentes y los procesos que han incidido en su constitución, para dilucidar campos de discusión, argumentos para las luchas sociales e insumos para la construcción de políticas sociales desde la equidad social.

- Problema

¿Cómo se han configurado históricamente las desigualdades sociales en la precarización de las condiciones laborales de las y los trabajadores en Costa Rica, durante el periodo comprendido entre 2010 y $2018 ?$

- Objetivos

1. Develar el contexto sociopolítico y económico que ha propiciado la proliferación de las desigualdades sociales en el mundo del trabajo.

2. Identificar las condiciones de precarización laboral de las y los trabajadores en Costa Rica.

3. Dilucidar alternativas y/o aportes para el goce equitativo de los derechos laborales.

\section{El contexto socio-político y económico y la proliferación de las desigualdades sociales en el mundo del trabajo}

El desarrollo de las sociedades y la interacción de los seres sociales, contiene un devenir sociohistórico, en el que se manifiestan diversos procesos sociales, políticos, económicos, culturales e ideológicos, que interactúan y demarcan el movimiento de la realidad. Ante esto, Lefebvre (1961) indica que, desde la concepción marxista del mundo, es fundamental contemplar la realidad más allá de la conciencia individualizada, es decir, considerar "las realidades naturales (la naturaleza, el mundo exterior); prácticas (el trabajo, la acción); sociales e históricas (la estructura económica de la sociedad, las clases sociales, etcétera)" (p. 6).

El contexto sociohistórico y las diferentes dimensiones en las que se desarrollan las sociedades, se encuentran teñidas de diversas ma- 
nifestaciones de desigualdad social, mediante la instauración de sistemas de dominación, entre los cuales destacan el colonialismo, el patriarcado y el capitalismo, expresados en procesos de discriminación, relaciones de poder y la visión del otro.

Por tanto, es necesario repensar algunas condiciones que han favorecido el establecimiento de ciertas visiones de sociedad en las cuales se gesta la proliferación de derechos humanos y justicia social, o el crecimiento de las desigualdades sociales en sus diferentes manifestaciones. Esto último, ha sido propiciado por los sistemas sociopolíticos instaurados en Costa Rica, relacionados con los procesos de producción capitalistas que tienen como objetivo principal el crecimiento económico, el aumento de la riqueza y la distribución desbalanceada de la misma.

Así, según Marx (1967), el capitalismo y su expansión suponen un proceso que apela a la producción de mercancías y plusvalías, en las que se demanda la subordinación del trabajo y sus condiciones a los intereses del capital. Por ende, se transforma la categoría "trabajo como mercancía", lo cual deriva en diferentes expresiones de explotación y apropiación, es decir, transita desde una acción para satisfacer necesidades básicas y reproducir las condiciones de vida - desde su concepción ontológica-, a una actividad humana a favor de la reproducción capitalista.

En América Latina se percibe actualmente condiciones laborales precarizadas en sus diferentes manifestaciones, que van desde el acceso al trabajo hasta las condiciones paupérrimas en las cuales se gestan las oportunidades de trabajo existentes. De esta forma, contar con un trabajo no es sinónimo de óptimas condiciones para desarrollarlo, ni para la óptima satisfacción de necesidades, lo cual, a su vez, perpetúa la brecha existente entre las clases sociales.

De esta manera, diferentes países han vivenciado los embates del capitalismo, con diversos escenarios propicios para su instauración y reproducción, que tienen sus mejores elementos en tiempos de crisis que el mismo sistema genera, pero requiere su reinstauración y/o apaciguar el descontento de las clases sociales trabajadoras.

Es necesario reconocer que la evolución del capitalismo acarrea una crisis estructural en diferentes coyunturas, que si bien genera cambios sustanciales en la comprensión de la categoría "trabajo", en el fondo lo percibido es una adaptabilidad a las demandas de las economías según su momento histórico, es decir, diferentes manifestaciones de dominación sujetas a los intereses del mercado.

Según Marx (1969), en el contexto capitalista el carácter concreto de la categoría "trabajo" como realización humana se reduce, en tanto su carácter abstracto se perpetúa y materializa en nuevas formas de explotación, en su reducción como una mercancía más, pero necesaria como mecanismo de sobrevivencia.

Así, las crisis económicas y sociales acaecidas a lo largo de la evolución del capitalismo se gestan en escenarios específicos. En Costa Rica, la industrialización, el modelo agroexportador, el modelo de sustitución de importaciones - desarrollista-, la globalización y el neoliberalismo, se presentan como formas específicas de desarrollo del modo de producción capitalista.

Dentro de las relaciones de poder, los países que poseían la hegemonía de los mercados y la generación de plusvalía se sujetan al resto con los mayores efectos adversos, al constituirse, estos últimos, en subordinados geopolíticos estratégicos para la libre movilidad del capital.

Por ende, a lo largo de la evolución del capitalismo parte de las principales repercusiones se concatenan en el mundo del trabajo que, por su misma lógica, socava las condiciones de vida de las personas; es decir, la desvaloración de la fuerza de trabajo se presenta como un hecho histórico, en constante transformación.

Sin embargo, las estrategias de liberación económica han reclutado múltiples figuras de alcance político, entre las que destaca la del Estado. Según Harvey (2007), la liberalización del capital, bajo el discurso de la apertura comercial mediante la transnacionalización, la inversión extranjera y la estandarización internacional, ha posibilitado la neoliberalización de los Estados a través de reformas estructurales, enfatizadas en la privatización, la competencia y la reforma de políticas y legislación establecidas en la regulación en los ámbitos económico, político y social, con lo cual se perpetúan las reformas en el ámbito laboral.

De esta manera, se transita desde un Estado empresario, benefactor o interventor, hasta un Estado neoliberal declarado como tal, en tanto su protagonismo, desde la lógica capitalista, ha propiciado su reducción en sentido amplio, desde que se constituyó como figura prio- 
ritaria para el desarrollo económico, influenciado legítimamente por organismos financieros internacionales.

Según Esquivel (2013), dichos procesos validaron la entrada en vigencia de un proyecto de globalización del mercado, inserto mediante programas como los de ajuste estructural, con énfasis en la flexibilidad laboral y financiera, en las actividades productivas y en la reducción de la intervención del Estado y la reforma del sector público. Lo anterior, con un claro interés por el detrimento de las clases trabajadoras y la reducción de sus garantías sociales.

De esta manera, se intensificaron procesos de liberalización de capital, la economía de libre mercado, la apertura comercial y la circulación de mercancías. Bajo estos parámetros y con el supuesto afán de la activación de la economía como medio para el desarrollo de las sociedades, se establecen convenios y pactos internacionales que terminan por obligar a los Estados a procesos neoliberales feroces.

Lo anterior se constituye en característica propia del capitalismo contemporáneo, el cual, según Tonet (2009), establece que las relaciones productivas están determinadas por la libre circulación de capital, aunque esto implique mecanismos violentos y reformas estructurales antipopulares.

Así, según Esquivel (2013), el reflejo del capitalismo contemporáneo en el escenario costarricense, se relaciona con:

Implementación de una política exterior que amplió los socios comerciales y la llegada de inversiones extranjeras directas.

Incentivo de la rama de servicios para gestar un encadenamiento con las demandas de empresas transnacionales, especialmente en áreas técnicas, tecnológicas, del sector financiero y turístico.

Declive de las bases de la seguridad laboral y social, en función de generar una ampliación en la llegada de empleadores de la fuerza de trabajo, por medio de su abaratamiento y vulnerabilidad.

Progresivos procesos de reducción de la planilla estatal, al amparo del argumento del déficit fiscal y la deuda externa.

Disminución y reconversión de la inversión social, transitando de políticas sociales de corte universal a focalizadas y selectivas. (Esquivel, 2012, citado en Esquivel, 2013, p. 85)
Esto evidencia el énfasis en el crecimiento del capital trasnacional y financiero.Por lo tanto, ante dicho panorama, pactos como el Tratado de Libre Comercio TLC EUCA son las líneas de desarrollo establecidas como óptimas para el crecimiento del país, situación que obvia el deterioro de las condiciones de vida de las clases trabajadoras, pues el objetivo es concentrar dicho crecimiento en las clases dominantes. Por ende, el accionar estatal se orienta a fortalecer la presencia del capital trasnacional, el fomento de la competitividad, la reducción del mercado interno y la implementación de reformas fiscales.

Según Casilda (2004), las demandas hacia los Estados se relacionaron con la expansión de las exportaciones, la apertura a la inversión extranjera, las privatizaciones de empresas públicas y el fortalecimiento jurídico de los derechos individuales (y de propiedad privada) frente a los colectivos.

Por tanto, se refleja la mercantilización y la privatización de derechos como la educación, el trabajo, la seguridad social, la vivienda, mismos que, con dicho escenario, reflejan los embates severos de esta visión de sociedad. Según Esquivel (2013), en el contexto del siglo XX y en el ámbito laboral, se gestaron condiciones asociadas con la flexibilidad laboral, la desprotección y el abaratamiento (la pérdida del valor real de los salarios). Mismas que en el contexto actual han aumentado, pues, según Tonet (2009), el capitalismo contemporáneo acumula a través de la fuerza de trabajo, por medio de formas cada vez más diversas de sobreexplotación, y se vale de cualquier medio para "aumentar la tasa de lucro obtenida por medio de una enorme intensificación de la explotación de los trabajadores" (p. 109).

Lo anterior se relaciona con la materialización de las desigualdades sociales, la exclusión y, en sentido más amplio, como manifestación de la cuestión social. Al respecto se menciona, "entender a la exclusión social como un fenómeno histórico-estructural relacionado con el proceso acumulativo vigente; y segundo, se postula que esta relación viene mediada por las desigualdades sociales generadas por tal proceso, siendo la exclusión su manifestación más extrema" (Pérez y Mora, 2006, p. 433).

De esta manera, las desigualdades sociales se constituyen en el ejercicio de las relaciones de poder entre las clases sociales; son expresiones de discriminación, vulnerabilización y fragilidad de carácter 
multidimensional, mismas que, a su vez, establecen diferencias de ciudadanía con el afán de legitimar su carácter político-legal en el ejercicio de derechos. Según refiere Baraibar (2000), lo anterior permite supeditar el otorgamiento de derechos a la constatación de dificultades personales, las que, a su vez, responsabilizan de forma individual a su realización personal, como alineación encubierta.

Por ende, sus expresiones en el ámbito laboral dejan sin efecto la comprensión de la exclusión en dicha realidad como desempleo estructural, pues se desvaloriza la fuerza de trabajo ante la necesidad de vender la misma como mecanismo de dependencia para obtener medios de sobrevivencia, lo que, según Antunes (2006), acarrea situaciones de desregulación, flexibilización y desdoblamiento de los derechos del trabajo, al apropiarse de su dimensión cognitiva y subjetiva.

Así, es necesario ahondar en dichas manifestaciones de desigualdad social en sus diferentes formas y su reflejo en las condiciones de vida de las y los costarricenses. En el siguiente apartado se explican algunas de estas y sus evidencias estadísticas.

\section{Las condiciones de precarización laboral en Costa Rica}

Reconocer condiciones laborales ha sido un proceso de diferentes configuraciones sociohistóricas, implica avances y retrocesos diversos según la perspectiva y la visión de mundo que se reproduzca en la comprensión de la categoría "trabajo". Los modelos sociopolíticos y económicos de los últimos años en el país han generado desigualdades sociales manifiestadas en la pauperización de los derechos laborales.

De esta manera, hablar de "derechos laborales" es reconocer a los individuos como sujetos de derechos y deberes, lo cual, a su vez, contrapone un modelo de Estado con un sistema sociopolítico e ideológico en particular, y con ambivalencias en su ejercicio de garantizar bienestar a su población trabajadora. Es decir, acoplar democracia, derechos y seguridad social al amparo del mercado, el neoliberalismo y la lógica de capital, es paradójico.

Al respecto se menciona, para el caso latinoamericano, que "no ha prevalecido de manera duradera la democracia ni se han garantizado todos los derechos civiles o políticos o se han desarrollado significati- vamente los derechos sociales para toda la población" (Del Valle, 2010, p. 240).

Por ende, se encuentran condiciones contradictorias, las cuales se debaten entre generación de plusvalía y supremacía hacia el mercado o el ejercicio del trabajo para la reproducción óptima de condiciones de vida. Así, la precariedad del trabajo y las manifestaciones de opresión y dominación son una constante en el escenario expuesto.

Según Morales (2011), existe una tendencia al crecimiento del desempleo y de la flexibilidad laboral (empleabilidad) en sus diversas manifestaciones (reducción de la cobertura de la seguridad social, precariedad salarial, informalidad, deterioro en la calidad de los puestos, subempleo), acentuados en tanto las clases trabajadoras terminan por aceptar dichas condiciones en el cometido de subsistir.

Es decir, con la acumulación de capital, la fuerza de trabajo se convierte en una mercancía más, lo cual, según Antunes (2001), implica que la clase que vive del trabajo deba vender su fuerza como una forma de subsistencia y reproducción social.

\section{Sin embargo:}

...la relación salarial no permite la satisfacción de las necesidades básicas ni la reproducción social. (...) el aumento del desempleo coloca cada vez más a una mayor cantidad de personas en esta condición de vulnerabilidad, además de la subcontratación y la integración de personas al empleo informal que van en aumento. (Campos, Chavarría, Vindas, 2009, p. 57)

De esta manera, según refiere Martínez (2008), se despliegan modalidades informales de trabajo remunerado, una crisis en el empleo formal -insuficiente y precario-, y el surgimiento del desempleo estructural. Por ende, la precarización de las condiciones laborales transita desde el desempleo hasta condiciones de flexibilidad e informalidad.

Así, esa acumulación de capital y la oferta del mercado laboral bajo el sistema político-ideológico no es capaz (ni es su prioridad) de asumir la fuerza laboral existente en términos de cantidad y de calidad. Según explica Jiménez (2012),

...la cantidad está asociada con el número de desocupados, mientras que la calidad está relacionada con los ocupados en empleos 
que se ejercen bajo situaciones de baja productividad, con escaso capital físico y/o humano y en actividades que están por fuera de la normatividad del mercado, como aquellas en las que se pagan salarios inferiores al mínimo establecido, en las que no se reconocen las prestaciones sociales o en las que se incumple con las jornadas laborales. (p. 115)

De esta manera, la precarización de las condiciones laborales se relaciona con la exclusión social, la afectación en las condiciones de vida, bajos ingresos, inestabilidad económica, limitado ejercicio de garantías sociales y exclusión de la legislación. Variables que, como se ha expuesto, tienen relación con aspectos estructurales, políticos, económicos, ideológicos y sociales, y que median a su vez con factores como la edad, el nivel educativo, el género, la ubicación geográfica (urbanorural), entre otros.

Lo anterior se relaciona con características propias de la empleabilidad, la cual descalifica la categoría "trabajo" en su sentido ontológico, pues, según Campos, Chavarría y Vindas (2009), su tendencia se centra en eliminar todas las regulaciones que sean obstáculos para el aumento de la competitividad y el crecimiento del mercado, por tanto, el empleo precario, temporal, subcontratado y tercerizado es recurrente.

En Costa Rica, el Instituto Nacional de Estadísticas y Censos (INEC) (2015) define el empleo informal como aquel en el que la persona asalariada no está inscrita en la seguridad social a través de patrón, o carece de remuneración, o se riere a aquella persona que labora por cuenta propia o tiene empresa no constituida (inscrita en el Registro Nacional de la Propiedad) y no lleva una contabilidad formal.

Aunado a esto, el INEC explica el subempleo como aquella circunstancia en la que las personas trabajadoras laboran menos de una jornada completa (menos de 40 horas) y desean trabajar más horas.

De esta forma, al repensar el desempleo se considera que trasciende la desocupación en sí o la carencia de ingreso económico, pues acarrea implicaciones a nivel integral, lo cual se manifiesta en desigualdades sociales, tanto a nivel individual como colectivo, y deriva en la demanda de intervención de diversos actores sociales en el cometido de atender las necesidades de las poblaciones.
Según Antunes (2001) y asociado a las condiciones laborales del siglo XXI, "la actual tendencia de los mercados de trabajo es reducir el número de trabajadores fijos, para emplear cada vez más una fuerza de trabajo que entra fácilmente y es despedida sin costos" (p. 57).

Así, es necesario considerar algunos de los datos estadísticos en Costa Rica respecto de las condiciones del trabajo. Según la Encuesta Nacional de Hogares (ENAHO) realizada por el INEC, para 2010 la fuerza de trabajo era de 2.051 .696 personas (que representaba el 59,1\% de la población de 15 años y más), con un 7,3\% de personas desempleadas.

De la población ocupada (1.902.164 personas) el 11,2\% estaba afectada por subempleo debido a insuficiencia de horas. Esta situación afectó proporcionalmente más a las mujeres (15\%) que a los hombres (9\%).

Aunado a esto, según la Encuesta Continua de Empleo (ECE) del INEC, para 2018 la fuerza de trabajo era de 2.459 .237 personas (que representaba el $63 \%$ de la población de 15 años y más), con un $12 \%$ de personas desempleadas.

De la población ocupada (2.165.323 personas), el 9\% estaba afectada por subempleo por insuficiencia de horas. Esta situación afectó proporcionalmente más a las mujeres $(12,7 \%)$ que a los hombres $(6,7 \%)$.

En el siguiente cuadro se presentan algunos datos del periodo en estudio arrojados por el INEC, respecto de la fuerza de trabajo, el desempleo y el subempleo.

Tabla 1.

Variaciones en el campo laboral.

\begin{tabular}{llllllllll} 
& 2010 & 2011 & 2012 & 2013 & 2014 & 2015 & 2016 & 2017 & 2018 \\
\hline $\begin{array}{l}\text { Fuerza de } \\
\text { trabajo. }\end{array}$ & $\begin{array}{l}2051 \\
696 .\end{array}$ & $\begin{array}{l}2122 \\
854\end{array}$ & $\begin{array}{l}2194 \\
291\end{array}$ & $\begin{array}{l}2241 \\
619\end{array}$ & $\begin{array}{l}2279 \\
775\end{array}$ & $\begin{array}{l}2242 \\
919\end{array}$ & $\begin{array}{l}2280 \\
989\end{array}$ & $\begin{array}{l}2200 \\
092\end{array}$ & 2459 \\
\hline $\begin{array}{l}\text { Tasa de } \\
\text { desempleo. }\end{array}$ & 7,3 & 10,4 & 9,8 & 8,3 & 9,7 & 9,6 & 9,5 & 9,3 & 12,0 \\
\hline $\begin{array}{l}\text { Porcentaje } \\
\text { de ocupados } \\
\text { con } \\
\text { subempleo. }\end{array}$ & 11,2 & 9,0 & 12,4 & 12,8 & 14,2 & 11,6 & 9,3 & 8,0 & 9,0 \\
\hline
\end{tabular}

Fuente: Elaboración propia basada en los datos de los IV trimestres de la Encuesta Continua de Empleo de los años en estudio. 
Aunado a esto, según la ECE 2018, el porcentaje de ocupados con empleo informal fue $44,9 \%$. Respecto del año anterior, el porcentaje de informalidad del país aumentó 3,8 pp.; variación originada principalmente por las mujeres en la informalidad y los trabajadores independientes. Asimismo, se observa que, tanto la ocupación como el desempleo, han aumentado en su mayoría producto del incremento en la oferta laboral, proveniente de la población fuera de la fuerza de trabajo que no trabajaba y no buscaba trabajo.

Sin embargo, lo anterior se relaciona con algunas particularidades desarrolladas en el periodo comprendido entre 2010-2018; según el Programa Estado de la Nación (2017), en este lapso la generación de empleo ascendió a 35 mil puestos anuales en promedio, de los cuales 31 mil fueron informales.

De igual manera, se identificó que la mayor parte del empleo informal fue de trabajadores independientes con bajo nivel educativo, lo cual se asume desde la dificultad de conseguir un empleo formal: se opta por un emprendimiento de manera irregular. Según el INEC (2015), desde 2012 ha existido una tendencia paulatina al aumento del empleo informal, el cual osciló entre el $36 \%$ y $45 \%$.

Junto con esto, el Programa Estado de la Nación (2017) indica que, para 2017, se registró la mayor pérdida de empleo de los últimos veinte años: 30.645 puestos de trabajo. Esta reducción se concentró en los grupos más vulnerables: personas no calificadas, microempresas, jóvenes entre 15 y 35 años de edad y mujeres.

\section{Así, el Programa Estado de la Nación (2018) concluye que:}

...las mejoras en materia educativa reducen la desigualdad. Entre 2010 y 2017 , en promedio un $47,1 \%$ de las personas que buscaron empleo por primera vez tenía al menos secundaria completa. La escasez de mano de obra calificada incrementa las remuneraciones para este grupo de la población, lo que a su vez aumenta las brechas de ingreso. Así pues, la inversión en educación podría generar avances significativos en la desigualdad de ingreso dentro de las ramas (p. 46)

De esta manera, se retoma el carácter movilizador de la educación en sentido amplio, pues trasciende las brechas de la accesibilidad económica y se fija en términos estructurales de la desigualdad social, aspectos que se retomarán más adelante.
Repensar estos datos conlleva necesariamente a considerar el efecto en el desarrollo humano de las poblaciones, pues, como se ha evidenciado, las condiciones fluctúan y pueden generar un aparente crecimiento económico para las personas, pero también se vislumbra que dichos aspectos son tendientes al deterioro de la calidad de vida de las personas, en detrimento de sus derechos y bienestar integral.

Ante esto, es necesario esclarecer, las transformaciones en el mundo del trabajo desde la institucionalidad, invisibilizan dichas condiciones como parte de la crisis estructural que el mismo sistema gesta en el recrudecimiento de las formas de explotación, y se responsabiliza a la clase trabajadora desde su posición individual, con diversas expresiones suscitadas en la contemporaneidad.

A su vez, de ahí se generan las categorías de ciudadanos, en tanto, en este ordenamiento político-estatal, hay quienes se constituyen como acreedores de derechos y quienes no. Por lo cual la comprensión de los derechos pierde su aprehensión desde las luchas sociales y se reduce a una posición de ciudadanía derivada desde la lógica del sistema capitalista.

Es decir, se brindan condiciones precarias de empleo, que en realidad generan mayor vulnerabilidad social, pues conducen a lo mencionado por Tavares (2018): "minimizar el costo de la fuerza de trabajo, en el mismo tiempo y maximizar la producción", es decir, la lógica y reproducción del sistema capitalista.

Por ende, según Valverde (2018), las cifras o los porcentajes de empleo no significan bienestar, es decir, formar parte del porcentaje de desempleo o de ocupados, en términos cualitativos de bienestar, no necesariamente representa variaciones significativas en el desarrollo de cada persona.

Según Castel (1995), existen diferencias en los ingresos laborales de quienes están en sectores de baja productividad y los sectores de media-alta productividad; a esto se agrega las diferencias existentes entre el sector público y el privado, en donde las condiciones laborales son fluctuantes y generan una rivalidad entre la misma clase trabajadora, al generarse el ideal que los derechos (por los cuales han luchado miles de personas a través de movimientos sociales) son privilegios, cuando 
en realidad el hecho de que no se gesten en ambos sectores es reflejo de los mayores embates de las políticas neoliberales.

\section{El Programa Estado de la Nación (2018) refiere:}

...el cumplimiento de las garantías laborales reporta pocos avances. Según la ENAHO 2017, un 41,4\% de las personas asalariadas goza de las seis garantías legalmente establecidas (aguinaldo, días pagos por enfermedad, vacaciones pagas, seguro de riesgos del trabajo, horas extra y aseguramiento directo en la $\mathrm{CCSS}^{2}$ ), mientras un

$17 \%$ no tiene acceso a ninguna. (p. 32)

Lo anterior se acentúa con lo planteado actualmente en el país con la Ley 9.635 "Ley de Fortalecimiento de las Finanzas Públicas", que, desde una lectura precisa, evidencia entre sus ejes mediadores el detrimento de lo público — con énfasis en el empleo-, presentado como generador de gastos y como culpable de la desigualdad social en el ámbito laboral. Premisas muy cómodas para ciertos sectores empresariales o "políticos"; y ante la opinión pública se ha presentado como necesidad en las regulaciones tributarias y fiscales.

De esta manera, se invisibilizan derechos (horarios, salarios, vacaciones, días libres, sin acceso a la seguridad social) y los deberes de los patrones. Asimismo, estos aspectos van a generar implicaciones en las condiciones de vida y, por ende, un deterioro acelerado en la salud de las personas.

El Programa Estado de la Nación (2018) apunta que los indicadores de oportunidades económicas y sociales mantuvieron un comportamiento desfavorable durante los últimos años: "desaceleración del crecimiento económico, pérdida histórica de empleos, deterioro de la seguridad y la convivencia ciudadana" (p. 19). En conjunto, es evidente que dichas variables tienen efectos en las condiciones de vida de la población, mayores índices de pobreza, menores posibilidades de acceso a la seguridad social y a la participación social, barreras estructurales para el acceso a la educación y a la atención en salud.

Asimismo, Aparicio (2006) señala que las condiciones precarias a nivel laboral, incluido el desempleo, han generado efectos en la salud

Caja Costarricense de Seguro Social (CCSS). física (mortalidad asociada a causas cardíacas) y mental (suicidios), hacinamiento y precariedad domiciliar, aumento de la violencia social e intrafamiliar y el crecimiento de las migraciones (tanto a nivel urbano-rural como internacional).

Aunado a esto, Naranjo (2009) explica que las causas del estrés son muchas y variadas, las cuales provienen de circunstancias tales como el ambiente social, la familia, el trabajo, el estudio, las relaciones interpersonales, entre otras.

Según el Consejo de Salud Ocupacional del Ministerio de Trabajo y Seguridad Social, en su Estadística de Salud Ocupacional (2016), en Costa Rica:

Además de los riesgos mecánicos, locativos y de higiene comúnmente reportados por la entidad aseguradora, otras investigaciones señalan que la población trabajadora costarricense experimenta estrés laboral, producto de situaciones laborales asociadas a una alta exigencia laboral con limitaciones de tiempo para desarrollarlo y escaso apoyo social y material para su desempeño. Aunado a una gran cantidad de tiempo dedicado al trabajo; que se agudiza con largos tiempos de traslado de la residencia al trabajo y viceversa. Estas percepciones de experimentar estrés laboral también se relacionan con molestias a la salud, principalmente el dolor musculo-esquelético en espalda, cuello, hombros y extremidades superiores. (p. 61)

A partir de lo expuesto, se insiste en que la precariedad en el mundo del trabajo forma parte de la desigualdad, la exclusión y la injusticia social, mismas que presentan sus efectos en el ámbito público y privado de la vida de las personas; es decir, es una afectación estructural, la cual incide en la cotidianidad. Por ende, dichos efectos nocivos no resultan responsabilidad exclusiva de las poblaciones y, por el contrario, demandan una atención estatal a paliar los efectos de la implementación y validación de un sistema sociopolítico capitalista, sesgado ante la supremacía del mercado.

De esta forma, la participación de las diversas poblaciones en el reconocimiento de garantías sociales depende del reconocimiento de las mismas y de la concientización política que permita el desarrollo de pensamientos críticos y disidentes a lo establecido oficialmente. 


\section{Alternativas para la validación y el goce equitativo de derechos laborales}

Las condiciones estructurales en las cuales se ha desarrollado el país y sus efectos en la precarización de los derechos laborales de las y los trabajadores, son escenarios de una coyuntura adversa y de grandes desafíos para reorientar el desarrollo humano en consonancia con la equidad y la justicia social. Así, repensar y cuestionar el devenir histórico de la realidad hace necesaria una reflexión política de amplia criticidad.

En el Programa Estado de la Nación (2018) se reconoce el aporte de la educación en la reducción de las brechas de desigualdad entre las diversas poblaciones. Sin embargo, es necesario considerar dicha apreciación desde la óptica de un desarrollo en función del bienestar de la cotidianidad de cada persona o en función de las demandas del mercado.

Según las políticas económicas y financieras instauradas en Costa Rica, el énfasis en el crecimiento económico orientado en la apertura comercial, promoción de exportaciones, prioridad por la inversión extranjera e ingreso de empresas trasnacionales genera que la formación y educación se orienten en función de los mercados.

Así, Serna y Botinelli (2017), en alusión a la intromisión de las elites empresariales mencionan, que:

Una interpretación sencilla para explicar el ascenso del "activismo empresarial democrático" (...) puede ser que su aparición se haya dado como resultado de la implantación de reformas económicas neoliberales que terminaron por situarlos en el centro del empoderamiento, en tanto agentes del cambio económico y del orden social. (párr. 2)

Por lo tanto, se asume al mercado y su expansión como fin último y como la estrategia a la que se debe dar respuesta desde los otros sectores de la sociedad. De ahí que haya proliferado la tecnificación adaptada a las necesidades del mercado, con énfasis en la producción y comercialización, y con un discurso hacia la sociedad que señala que esta es la alternativa idónea para la reproducción óptima de las condiciones de vida.

Según Morales (2011), "paralelamente a este cambio en el estilo nacional de desarrollo que ha experimentado el país, se han dado cambios en el desarrollo de la educación en todos sus niveles. Desde la educación inicial hasta la superior" (p. 8). El mismo autor explica que esto se evidencia en mayor segregación en el acceso a la educación, menor financiamiento para el sistema educativo público, poca regulación sobre la educación privada superior, sobreoferta de profesionales de ciertas áreas.

Ante esto, el énfasis se instaura en la formación de una fuerza laboral a disposición del mercado, con lo cual se favorece la privatización laboral y educativa, que genera la pauperización de las condiciones de vida y la reproducción de la idea de que esto depende de cada persona en su construcción individual. De esta forma, la opción de la educación, incluida la superior, implica decisiones, las cuales, en la cotidianidad, obvian los aspectos estructurales, de carácter político, económico, social, cultural e ideológico, y que, por ende, responsabilizan a cada persona de su "esfuerzo" para acceder a la educación.

Bajo esta lógica, derechos como la educación y el trabajo se convierten en herramientas para el lucro, los cuales, bajo esa absorción del pensamiento crítico, hacen creer que es válido e inclusive necesario. Por tanto, es indispensable la generación de espacios que permitan reflexionar acerca del desarrollo de la educación y del espacio laboral, pues ninguno de estos se encuentran dados naturalmente.

Mujica (2016) retomaba "la intromisión en el campo del pensamiento" (párr. 31) y el significado de la explosión de la tecnología y su uso según la intencionalidad política; lo anterior es un aspecto que, según Valverde (2019a), se asocia con la pérdida del pensamiento propio, del cuestionamiento, y de que las acciones desarrolladas actualmente tienen una tendencia normalizada, como resultado del impacto de los grandes sistemas de dominación en los procesos sociohistóricos de la cotidianidad humana.

Por tanto, la educación puede construirse en dos vías: como un proceso programático, mercantilizado y construido en función del mercado - desde lucrar con la formación hasta servir a las demandas del mercado-, o, por el contrario, como un hecho movilizador de pensamiento, con conciencia de clase y como un eje articulador para una sociedad justa, equitativa e igualitaria.

Según explica Morales (2011), este contexto genera una consecuencia relacionada con: 
...la poca capacidad de identificación que poseen los individuos aislados, para agruparse, identificarse con una causa o con un grupo (...) esta falta de cohesión social, y de integración, es plausible que esté relacionada con la poca capacidad de desarrollar identificación y sentido de pertenencia respecto del grupo laboral al cual se pertenece. (pp. 18-19)

A esto se agrega que, más que pertenencia a un grupo laboral, es precisamente el reconocimiento como clase trabajadora, como personas con intereses colectivos. De esta manera, es necesario de considerar el protagonismo de los movimientos sociales y su relación con lo expuesto anteriormente.

Según Menjivar (2007), desde la perspectiva de los sectores populares, "el accionar de los movimientos se dirige a cuestionar de manera fragmentaria o absoluta las estructuras de dominación prevalecientes y su voluntad implícita es transformar parcial o totalmente las condiciones de crecimiento social" (p. 6). Sin embargo, este mismo autor explica que, en Costa Rica, durante la última década se ha gestado la institucionalización del conflicto, lo cual termina por expresarse en la criminalización de la protesta social y en el desarrollo de procesos burocráticos para definir el ejercicio de derechos.

En Costa Rica, según Valverde (2019a), un ejemplo reciente de movilización social y de un impacto antagónico a los intereses colectivos es la lucha desarrollada durante 2018 (y que a la fecha distintos grupos sociales le consideran una lucha vigente) contra el proyecto de Ley 20.580 conocido como el “Combo fiscal”, actualmente Ley N 9.635 "Ley de Fortalecimiento de las Finanzas Públicas", la cual contiene una serie de reformas tributarias, con un importante impacto en las poblaciones más vulnerables y laboralmente en el sector público y privado.

Según la Asociación Nacional de Empleados Públicos y Privados ANEP (2019), dicho proceso gesta cambios en materia de derechos laborales otorgados, en la constitución del derecho a huelga y a la negociación colectiva, y da pie al crecimiento hegemónico del sector financiero y bancario a costa de la clase trabajadora.

Pleyers (2018) hacía alusión a la existencia de la esclavitud del pensamiento; y como los movimientos sociales "tienen estrategias no solo para tener un impacto en las decisiones políticas, sino también para formatear las mentalidades y las subjetividades de la gente y llegar a imponer una hegemonía ideológica (Gramsci, 2013, citado en Pleyers, 2018, p. 101)". Lo anterior, asociado con el proceso de constitución de los movimientos sociales y su vínculo con la educación y el pensamiento crítico, hace explícita la necesidad de repensar desde cuál perspectiva se están instaurando.

Pues los proyectos sociopolíticos que convergen actualmente, se constituyen antagónicos y se articulan desde visiones de mundo diferentes, con lo cual el vínculo existente entre derechos - como la educación, el trabajo y los movimientos sociales- pueden gestarse reivindicativos para el bienestar cotidiano o desiguales, situación que no depende exclusivamente de la responsabilidad personal.

Bringel (2019) planteó la siguiente interrogante: “¿por qué determinados sectores de la población que vienen del campo popular, terminan pensando que un auxilio de Estado es un privilegio y no un derecho?". Esta pregunta sigue latente, pues una de las diferencias más evidentes en las luchas actuales en el país, es que la movilización no se genera en todos los actores o poblaciones, y se propicia una división de los mismos sectores populares, ya que existe una dicotomía entre lo individual y lo colectivo, entre la vida privada-cotidiana y lo político, al perderse el proceso de cuestionar la intencionalidad política del accionar cotidiano.

Así, el arraigo de los sistemas de dominación hegemónicos y la influencia de la tecnología y de las redes sociales, ha hecho que muchas personas validen información sin cuestionarla; es la esclavitud del pensamiento, lo cual es prioritario de revertir en aras de validar derechos desde la colectividad.

Actualmente, según Valverde (2019b), la concentración de poder y de riqueza se estima indispensable a costa de lo que sea y de quien sea, lo cual da espacio a la división de clases sociales, a la visión del otro, al individualismo y, por ende, a la pérdida de la colectividad. De esta forma, la satisfacción de necesidades y la validación de derechos humanos es un proceso complejo, pues se establecen categorías de personas: unas con derechos, otras con privilegios y otras para las que los derechos se les cuestionan como privilegios.

Por ende, según el mismo Valverde (2019b), se debilita la democracia, se censura la protesta social y los movimientos sociales, al punto 
de criminalizar las luchas por los derechos de las poblaciones, hechos que el mal uso de los medios de comunicación y de las redes sociales han impulsado.

De ahí que la educación tenga una importancia tan grande en la construcción de democracia y de pensamiento consciente y crítico, aquella democracia desarrollada en las aulas, en las calles y en las comunidades. Pues la educación debe garantizarse como un derecho individual y colectivo, en tanto:

...sin democracias populares, sin democracias comprometidas en la ampliación de derechos no existe la posibilidad de sostener el derecho a la educación superior. La democracia implica que se cuestionen los propios modelos de desarrollo cuando estos son desiguales, injustos e inequitativos. (Diker, 2018)

De esta manera, el ejercicio en pleno de unos derechos genera aportes para el goce de otros, por tanto, existe una relación consecuente entre ellos. Así, las alternativas que se gesten para reducir la desigualdad en materia laboral deben pensarse en conjunto y en interacción con otras áreas: tal es el caso de la educación y del desarrollo de los movimientos sociales.

Asimismo, los derechos laborales, en su ejercicio pleno o en su precarización, deben repensarse desde la incidencia de la educación en sentido crítico y desde la movilización colectiva, de tal forma que, ante coyunturas como las actuales, prevalezca una visión de mundo tanto individual como colectiva, orientada a reivindicar los derechos de las personas y la satisfacción equitativa de sus necesidades, con lo cual se permita la reproducción de las condiciones de vida en aras de la igualdad y la justicia social.

\section{Conclusiones}

En Costa Rica, en el ámbito laboral, hoy se registran los mayores índices de desempleo de los últimos 10 años, lo cual se refleja en el estancamiento en el desarrollo social del país; mismo que, desde el discurso oficial, se expresa con avances fundamentales, pero que en la realidad de las clases sociales vulneradas no se evidencia.

$\mathrm{Al}$ considerar lo anterior se comprende que aquellos procesos tendientes a la justicia y equidad social se han supeditado a las demandas de lo económico y el mercado; con lo cual se explica que las acciones político-estatales se encuentren en consonancia con las demandas de las elites empresariales. Por tanto, los efectos del TLC como generador de empleo son residuales y evidencian un amplio deterioro en el mundo del trabajo como categoría ontológica y transformadora del ser social, además de un efecto adverso de dicha decisión político-empresarial, ya predicha por los movimientos sociales contra el TLC años atrás.

De esta manera, la entrada en vigencia de la Ley de Fortalecimiento de Finanzas Públicas en Costa Rica hace pensar que sus efectos en el desarrollo social del país serán escasos, pues el escenario en el cual se gesta se encuentra vulnerado y asimismo tiene su base en una decisión político-empresarial, lejana a los intereses de las clases trabajadoras.

Aunado a esto, otro sesgo en relación con la generación de desarrollo social, es que el bienestar de la población se encuentra supeditado únicamente al crecimiento económico, de ahí se justifican los procesos de dependencia al mercado y al sector financiero; reproducir lo anterior es fragmentar la realidad; por lo tanto, es necesario considerar críticamente las implicaciones en un nivel estructural y como un todo indivisible.

Por otro lado, es necesario repensar el protagonismo de la educación como un ente movilizador y un derecho humano, y no como derecho sujeto de explotación, a través del lucro en la formación y como herramienta en función del mercado. Aunado a esto, se introducen otros aspectos importantes, asociados con los intereses de las personas en el ámbito educativo.

El ejercicio del derecho a la educación tiende a ser sesgado por el sistema imperante, que define e instaura aquellas carreras en las cuales deben formarse las personas según las necesidades del mercado; por lo cual, los intereses personales a partir de la autonomía suelen deslegitimarse y son redireccionados.

Por tanto, la divergencia en considerar la profesionalización de las personas en ciertas disciplinas como una necesidad y no en otras, está en que social, política y económicamente solo ciertas profesiones tienen la posibilidad de insertarse en el mercado laboral y ser remuneradas (al menos en el ideal), de tal manera que se promueva la satisfacción de necesidades básicas. 
Sin embargo, lo anterior no necesariamente parte de la remuneración según la fuerza de trabajo invertida, pues, de ser así, es probable que muchas personas desarrollaran actividades laborales reconocidas actualmente como de baja calificación (pues se estima que solo la formación académica e institucional es válida de ser remunerada), pero ellas también son indispensables (tal es el caso de la agricultura).

Asimismo, el reconocimiento del trabajo como una categoría fundante, que permite la movilización de las condiciones de vida y, por ende, como un derecho producto de diversas luchas sociales, tiende a obviarse y entenderse como un hecho ahistórico. Por tanto, es necesario repensar que el derecho al trabajo y a óptimas condiciones no fue dado, sin que implica una lucha constante que facilite el bienestar integral.

Los efectos en el deterioro del desarrollo social, a partir de las condiciones precarias de trabajo, se reflejan tanto en el ámbito estructural como en la cotidianidad de las personas. De ahí que el deterioro en las condiciones de salud de las personas se refleja desde la limitación de adquirir un trabajo hasta el desempeño de una labor distinta de los intereses personales o para lo cual se estudió; o, por el contrario, una labor en condiciones adversas.

Como se ha mencionado y desde una perspectiva integral de las personas, la violación a un derecho u otro va a incidir en la totalidad de las condiciones de vida; por lo tanto, los efectos en la salud no se dan solo a nivel físico sino también en el ámbito emocional; muestra de esto son los altos índices de estrés, depresión y violencia.

Por ende, es clara la responsabilidad estructural e histórica en la instauración de condiciones de vida precarizadas, que se relacionan con el deterioro de la amplitud de derechos humanos, y entre ellos pero no aislados, los derechos laborales.

Asimismo, la movilización hacia las condiciones de equidad y justicia social no es responsabilidad exclusiva de las poblaciones; sin embargo, para paliar los efectos de dichas estructuras se requiere personas con interés por cuestionar lo establecido, pues las estructuras no se mueven solas y ha sido producto de las luchas sociales que se han generado reivindicaciones.
De esta forma, es fundamental promover la educación, para pensar y cuestionar lo establecido, los discursos, las normas y los procesos, y que, por tanto, se facilite la instauración de condiciones de vida asociadas con la aprehensión de la igualdad, la equidad y la justicia social, enfocadas y en atención a los intereses de las clases trabajadoras, en el ejercicio pleno de los derechos humanos.

\section{Bibliografía}

Antunes, R. (2001). ¿Adiós al Trabajo? Ensayo sobre las metamorfosis y la centralidad del mundo del trabajo. Brasil: Cortés Editora.

Antunes, R. (2006). El caracol y su concha: ensayo sobre la nueva morfología del trabajo. Buenos Aires, Argentina: Boitempo.

Aparicio, A. et al. (2006). Efectos psicosociales del desempleo. Revista de Investigación Social, II(3), 67-82. Recuperado de http:// www.economia.unam.mx/profesores/aaparicio/Efectos. pdf.

Asamblea Legislativa de la República de Costa Rica (4 de diciembre del 2018). Ley de Fortalecimiento de las Finanzas Públicas ( $\mathrm{N}^{\circ}$ 9.635). Diario Oficial La Gaceta. Recuperado de https://www.hacienda.go.cr/docs/5c07dd2965e11_ ALCA202_04_12_2018.pdf

Asociación Nacional de Empleados Públicos y Privados (ANEP) (25 de marzo 2019). 25 conclusiones: Análisis del deterioro de las condiciones laborales a partir de la ley del combo fiscal. Recuperado de https://anep.cr/25-conclusiones-analisis-deldeterioro-de-las-condiciones-laborales-a-partir-de-la-leydel-combo-fiscal/.

Baráibar, X. (2000). Algunos aportes para la discusión sobre exclusión social. Instituto Nacional del Menor - División Social.

Bringel, B. (2018). Movimientos sociales y la nueva geopolítica de la indignación global. Protesta e indignación global. Los movimientos sociales en el nuevo orden mundial. Buenos Aires: CLACSO/FAPERJ. Recuperado de http://biblioteca.clacso. edu.ar/clacso/se/20171204044413/Protesta_e_indignacion_global.pdf

Bringel, B. (2019). Clase Profesor Breno Bringel. [Grabado por el Consejo Latinoamericano de Ciencias Sociales] CLASE 9 - Movimientos sociales y el nuevo ciclo político en América Latina. 
[audio digital]. Recuperado de https://www.youtube.com/ watch?v=mzJBe6MIha0\&feature=youtu.be.

Campos, Chavarría y Vindas. (2009). Condiciones de empleo y desempleo de la población del cantón de Parrita, una aproximación al análisis desde la categoría trabajo. Tesis de grado, Universidad de Costa Rica. Recuperado de http://www.ts.ucr.ac.cr/ binarios/tfglic/tfg-l-2009-08.pdf.

Casilda, R. (2004). América Latina y el Consenso de Washington. España: Boletín Económico de ICE, (2803).

Castel, R. (1995). La metamorfosis de la cuestión social. Una crónica del salario. México: Editorial Paidós.

Consejo de Salud Ocupacional, Ministerio de Trabajo y Seguridad Social. (2016). Estadísticas de salud ocupacional, Costa Rica. Recuperado de https://www.cso.go.cr/documentos_relevantes/consultas/Estadisticas\%20CSO\%202016.pdf

Del Valle, A. (2010). Informalidad y modelos de bienestar en américa latina. Revista Política y Sociedad, 47(3), 239-261. Recuperado de https://revistas.ucm.es/index.php/POSO/article/ view/POSO1010330239A.

Diker, G. (2016). Clase magistral Gabriela Diker Curso Internacional: América Latina, ciudadanía derechos e igualdad. [Grabada por el Consejo Latinoamericano de Ciencias Sociales]. CLASE 10 - Democracia, derechos y justicia social [audio digital]. Recuperado de https://www.youtube.com/ watch?v=XRG7gxB7IQw.

Esquivel, F. (2013). Neoliberalismo en Costa Rica: secuelas en la cuestión social durante el siglo XX. Revista Cátedra Paralela, (9), 76-101. Recuperado de http://www.catedraparalela.com.ar/ images/rev_articulos/arti00121f001t1.pdf

Harvey, D. (2007). Breve Historia del neoliberalismo. España: Ediciones Akal.

Instituto Nacional de Estadísticas y Censos. (2013). Encuesta Continua de Empleo Indicadores del Mercado Laboral Costarricense cuarto trimestre 2013. Recuperado de http://www.inec. go.cr/sites/default/files/documentos/empleo/estadisticas/ resultados/reempleoece2013-lvtri-07.pdf

Instituto Nacional de Estadísticas y Censos. (2014). Encuesta Continua de Empleo Indicadores del Mercado Laboral Costarricense cuarto trimestre 2014. Recuperado de http://www.inec. go.cr/sites/default/files/documentos/empleo/estadisticas/ resultados/reempleoece2014-lvtri-11.pdf.

Instituto Nacional de Estadísticas y Censos. (INEC, 2010). Encuesta Nacional de Hogares. Recuperado de http://www.inec.go.cr/ sites/default/files/documentos/empleo/publicaciones/reenaho2010-03.pdf.

Instituto Nacional de Estadísticas y Censos. (INEC, 2015). Panorama del empleo informal en Costa Rica Caracterización al IV Trimestre 2015. Recuperado de sistemas.inec.cr/pad4/index. php/catalog/167/download/1651.

Instituto Nacional de Estadísticas y Censos. (INEC, 2017). Encuesta continua de empleo al primer trimestre 2017. Recuperado de http://www.inec.go.cr/sites/default/files/documetosbiblioteca-virtual/reece-i-t-2017.pdf.

Instituto Nacional de Estadísticas y Censos. (INEC, 2018). Encuesta Continua de Empleo al cuarto trimestre de 2018. Recuperado de http://www.inec.go.cr/sites/default/files/documetosbiblioteca-virtual/reeceivt2018.pdf.

Jiménez, D. (2012). La informalidad laboral en América Latina: ¿explicación estructuralista o institucionalista? Cuadernos de Economía, 31(58), 113-143. Recuperado de http://www.scielo. org.co/pdf/ceco/v31n58/v31n58a06.pdf.

Lefebvre, H. (1961). Introducción al marxismo. Buenos Aires, Argentina: Eudeba.

Martínez, J. (2008). Domesticar la incertidumbre en América Latina: mercado laboral, política social y familias. Recuperado de http://bibliotecavirtual.clacso.org.ar/Costa_Rica/iisucr/20120726031307/Domesticar.pdf.

Marx, C. (1967). La Mercancía. El Capital. Crítica a la Economía Política. Tomo I. México: Editorial Liberación Allende.

Marx, C. (1969). Menjívar, M. (2007). La investigación de los movimientos sociales en perspectiva histórica: elementos para el debate. Revista Intercambio, 4(5), 5-12. Recuperado de https://revistas.ucr.ac.cr/index.php/intercambio/article/ download/4013/3877/.

Ministerio de Comercio Exterior. (2004). Tratado de Libre Comercio República Dominicana-Centroamérica-Estados Unidos: documento explicativo. Recuperado de http://www.sice.oas.org/ tpd/usa_cafta/studies/usaexplicativo_s.pdf. 
Morales, C. (2011). Mercado laboral, educación superior y formación docente en Costa Rica. Revista actualidades investigativas en educación, 11(1), 1-27. Recuperado de https://revistas.ucr. ac.cr/index.php/aie/article/view/10165/18022.

Mujica, J. (marzo, 2016). América Latina, ciudadanía, derechos e igualdad. Trabajo presentado en el Curso Internacional América Latina: ciudadanía, derechos e igualdad del Consejo Latinoamericano de Ciencias Sociales, Buenos Aires, Argentina. Recuperado de http://clacsovirtual.org/clasico/pluginfile. php/42349/mod_resource/content/1/Clase\%201\%20-\%20 Transcripcio\%CC\%81n\%20Conferencia\%20Mujica.pdf.

Naranjo, M. (2009). Una revisión teórica sobre el estrés y algunos aspectos relevantes de éste en el ámbito educativo. Revista educación, 33(2), 171-190. Recuperado de https://revistas.ucr. ac.cr/index.php/educacion/article/download/511/527/.

Perez, J. y Mora, M. (2006). Exclusión social, desigualdades y excedente laboral. Reflexiones analíticas sobre América Latina, Revista Mexicana de Sociología, 68(3), 431-465. Recuperado de http://www.redalyc.org/articulo.oa?id=32112601002.

Pleyers, G. (2018). Los movimientos sociales como productores de la sociedad. Movimientos sociales en el siglo XXI. Buenos Aires: CLACSO. Recuperado de http://biblioteca.clacso.edu. ar/clacso/se/20181101011041/Movimientos_sociales_siglo_XXI.pdf.

Programa Estado de la Nación. (2017). Estado de la nación en desarrollo humano sostenible. Costa Rica: Programa Estado de la Nación. Recuperado de https://estadonacion.or.cr/2017/ descargas.html.

Programa Estado de la Nación. (2018). Informe Estado de la nación en desarrollo humano sostenible 2018, Resumen. Costa Rica: Programa Estado de la Nación. Recuperado de https://www. estadonacion.or.cr/2018/assets/resumen-en.pdf.

Serna, M. y Botinelli, E. (2017). El poder de las elites empresariales en la política latinoamericana. Recuperado de https://www.clacso.org.ar/megafon/pdf/Megafon_15_2_Serna_Botinelli.pdf.

Tavares, L. (2018). Clase 6: Las consecuencias del neoliberalismo en la desigualdad en América Latina. Seminario virtual La política social universal en la superación de la desigualdad, del Consejo Latinoamericano de Ciencias Sociales y la Facultad
Latinoamérica de Ciencias Sociales. Recuperado de http:// clacsovirtual.org/clasico/pluginfile.php/41677/mod_resource/content/2/Clase\%206_Tavares.pdf.

Tonet, I. (2009). Expressões socioculturais da crise capitalista na atualidade. En: Serviço Social: Direitos Sociais e Competências Profissionais. Brasília D.F., Brasil: Conselho Federal de Serviço Social (CFESS), Associação Brasileira de Ensino e Pesquisa em Serviço Social (ABEPSS).

Valverde, M. (2018). Foro clase 6 Seminario La Política Social Universal en la superación de la desigualdad. Consejo Latinoamericano de Ciencias Sociales y la Facultad Latinoamérica de Ciencias Sociales.

Valverde, M. (2019a). Foro clase 9 Curso Internacional en políticas públicas para la igualdad en América Latina. Consejo Latinoamericano de Ciencias Sociales y la Facultad Latinoamérica de Ciencias Sociales.

Valverde, M. (2019b). Foro clase 11 Curso Internacional en políticas públicas para la igualdad en América Latina. Consejo Latinoamericano de Ciencias Sociales y la Facultad Latinoamérica de Ciencias Sociales. 